\title{
Highly Selective Differential Pulse Voltammetric Determination of Uric Acid using Modified Glassy Carbon Electrode
}

\author{
Kaveh Movlaee $^{1}$, Parviz Norouzi $^{1,2, *}$, Hadi Beitollahi $^{3}$, Morteza Rezapour $^{4}$, Bagher Larijani $^{5}$ \\ ${ }^{1}$ Center of Excellence in Electrochemistry, University of Tehran, Tehran, Iran \\ ${ }^{2}$ Biosensor Research Center, Endocrinology \& Metabolism Molecular-Cellular Sciences Institute, \\ Tehran University of Medical Sciences, Tehran, Iran \\ ${ }^{3}$ Environment Department, Institute of Science and High Technology and Environmental \\ Sciences, Graduate University of Advanced Technology, Kerman, Iran \\ ${ }^{4}$ IP Department, Research Institute of the Petroleum Industry (RIPI), P.O. Box 14665-137, Tehran, \\ Iran \\ ${ }^{5}$ Diabetes Research Center, Endocrinology \& Metabolism Clinical Sciences Institute, Tehran \\ University of Medical Sciences, Tehran, Iran \\ *E-mail: norouzi@khayam.ut.ac.ir
}

doi: $10.20964 / 2017.04 .06$

Received: 31 December 2016 / Accepted: 30 January 2017 / Published: 12 March 2017

\begin{abstract}
A nanocomposite was prepared by incorporating $\mathrm{Fe}_{3} \mathrm{O}_{4}$ onto graphene sheets, and then a layer of $\mathrm{SiO}_{2}$ were deposited on the surface of the $\mathrm{Fe}_{3} \mathrm{O}_{4} /$ graphene composites. This modified electrode was used for electrochemical determination of uric acid (UA). Cyclic voltammetry, differential pulse voltammetry and chronoamperometry were used to investigate the electrochemical behavior of uric acid at the chemically modified electrode. According to the results, $\mathrm{Fe}_{3} \mathrm{O}_{4} @ \mathrm{SiO}_{2} / \mathrm{GO} / \mathrm{GCE}$ showed high electrocatalytic activity for uric acid oxidation, producing a sharp oxidation peak current at $330 \mathrm{mV} v s$. $\mathrm{Ag} / \mathrm{AgCl}$ reference electrode at $\mathrm{pH}$ 7.0. The peak current was linearly dependent on uric acid concentration over the range of 0.5 to $250.0 \mu \mathrm{M}$ with the detection limit $(3 \sigma)$ of $0.07 \mu \mathrm{M}$. The proposed method was successfully applied as a rapid, highly selective, simple, and precise one to determine uric acid in urine.
\end{abstract}

Keywords: Uric acid; $\mathrm{Fe}_{3} \mathrm{O}_{4} @ \mathrm{SiO}_{2} / \mathrm{GO}$ nanocomposite; Graphene; Glassy Carbon Electrode; Differential pulse voltammetry

\section{$\underline{\text { FULL TEXT }}$}

(C) 2017 The Authors. Published by ESG (www.electrochemsci.org). This article is an open access article distributed under the terms and conditions of the Creative Commons Attribution license (http://creativecommons.org/licenses/by/4.0/). 